\title{
Partes não-integrantes da carcaça de tourinhos alimentados com diferentes níveis de concentrado na dieta
}

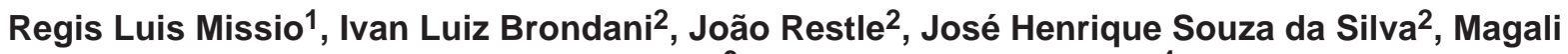 \\ Floriano da Silveira ${ }^{3}$, Viviane Santos da Silva ${ }^{4}$
}

\footnotetext{
${ }^{1}$ Programa de Pós-graduação em Zootecnia - Universidade Estadual do Estado de São Paulo, campus Jaboticabal.

2 Departamento de Zootecnia - Universidade Federal de Santa Maria.

3 Programa de Pós-graduação em Zootecnia - Universidade Federal de Santa Maria.

${ }^{4}$ Graduação em Zootecnia - Universidade de Santa Maria.
}

RESUMO - O objetivo neste estudo foi avaliar as partes não-integrantes da carcaça de tourinhos abatidos entre 14 e 16 meses de idade alimentados com diferentes níveis de concentrado na dieta. Os animais foram terminados em confinamento até atingirem em média $400 \mathrm{~kg}$ de peso vivo. Foram utilizados 16 tourinhos alimentados com 22, 40, 59 ou $79 \%$ de concentrado na dieta, distribuídos inteiramente ao acaso, com quatro repetições por tratamento. A idade e o peso médio inicial dos animais foram de 9,32 meses e 192,44 kg, respectivamente. O peso de corpo vazio (PCVZ) e o rendimento de carcaça expresso em valores ajustados para o PCVZ foram similares entre os níveis de concentrado na dieta. O aumento no nível de concentrado na dieta promoveu diminuição linear do peso absoluto de intestino e aumentos lineares dos pesos absolutos da gordura ruminal e do abomaso. Quando os componentes foram expressos em valores ajustados para PCVZ e peso de abate (PA), verificaram-se aumentos lineares para pesos de patas, coração, intestinos, gordura de toalete, gordura do rúmen, conteúdo do trato gastrintestinal e conteúdo de gordura interna e diminuição linear do peso de cabeça e omaso com o aumento do nível de concentrado na dieta. O peso de abomaso foi quadraticamente influenciado pelo nível de concentrado, com valores mínimos estimados para os níveis de 68,0;66,7 e 69,2\% de concentrado na dieta, em relação ao peso absoluto, ajustado para o PCVZ e PA, respectivamente. O aumento do nível de concentrado de 22 para $79 \%$ promoveu aumento nos pesos relativos do conteúdo do trato gastrintestinal e gordura interna e não influenciou o conjunto dos órgãos internos, o peso de corpo vazio e o rendimento de carcaça ajustado para o PCVZ de tourinhos abatidos aos 14-16 meses com $400 \mathrm{~kg}$.

Palavras-chave: couro, gordura interna, peso de corpo vazio, rúmen-retículo

\section{Non-integrant components of the carcass from young bulls fed different concentrate levels}

\footnotetext{
ABSTRACT - The objective of this trial was to evaluate the non-integrant body components of the carcass from young bulls slaughtered at 14-16 months of age, fed different concentrate levels in the diet. The animals were feedlot finished until reaching $400 \mathrm{~kg}$ of body weight. Sixteen bulls were randomly distributed into four treatments: 22; 40; 59 or $79 \%$ concentrate in the diet. The initial average age and weight were 9.3 months and $192.4 \mathrm{~kg}$, respectively. The empty body weight (EBW) and carcass dressing ajusted for empty body weight were similar among the different concentrate levels. The increase in the concentrate level in the diet promoted linear decrease for intestine absolute weight, and linear increase for ruminal and abomasum absolute fat weight. When the components were expressed as adjusted EBW values and slaughter weight (SW), linear increases were observed for weight of feet, heart, intestine, trim fat, ruminal fat, gastrintestinal tract content and internal fat, and linear decreases were observed for weight of head and omasum as the concentrate level increased. The response of the abomasum weight according to the concentrate level was quadratic, with the minimum values estimated for the concentrate levels of 68.0, 66.7 and $69.2 \%$, in relation to the absolute weight, adjusted for EBW and SW, respectively. The increase in the concentrate level from 22 to $79 \%$ increased the ajusted weights of gastrintestinal tract content and internal fat; however, it did not affect the total internal organs, empty body weight and carcass dressing ajusted for empty body weight of bulls slaughtered at 14-16 months of age with $400 \mathrm{~kg}$.
}

Key Words: empty body weight, hide, internal fat, rumen-reticulum 


\section{Introdução}

Atualmente o Brasil é considerado no mercado internacional como o maior exportador de carne bovina, em razão do tamanho do seu rebanho comercial, das grandes áreas de pastagens, da elevada produção de grãos e seus subprodutos e do aumento da produtividade de $2,5 \%$ por ano na última década (Anualpec, 2006), relacionado ao desenvolvimento da pesquisa científica no País.

O suprimento das exigências nutricionais em bovinos é importante para viabilizar a produção pecuária. Entretanto, no Brasil, a formulação de dietas balanceadas ainda exige estimativas das exigências nutricionais obtidas em outros países, como EUA, França e Nova Zelândia. Este fato pode muitas vezes comprometer o adequamento das dietas às necessidades nutricionais dos animais, visto que as estimativas dos requerimentos nutricionais foram obtidas nestes países por meio de pesquisas realizadas em condições de criação, genótipos, pastagens e climatologia diferentes das condições brasileiras.

Em estudos de exigências energéticas dos animais, a determinação do tamanho dos órgãos internos é importante, pois diferenças nas partes não-integrantes da carcaça podem induzir variações nos requisitos energéticos para mantença (Owens et al.,1995). Pacheco et al. (2005) observaram relação negativa entre peso dos componentes externos e trato digestivo com o rendimento de carcaça. Por outro lado, diversos autores (Owens et al., 1993; Ferrel \& Jenkins, 1998) demonstraram que animais com maiores pesos de órgãos vitais, principalmente fígado, e maior acúmulo de gordura interna são energeticamente mais exigentes. Além disso, a avaliação dos componentes do corpo vazio em bovinos pode ser importante para o entendimento das características relacionadas ao desempenho e carcaça, no entanto, poucos estudos foram realizados.

Este estudo foi realizado com o objetivo de avaliar partes do corpo não-integrantes da carcaça de tourinhos superjovens terminados em confinamento com diferentes níveis de concentrado na dieta e abatidos aos 14-16 meses de idade.

\section{Material e Métodos}

O trabalho foi realizado no período de 30/07 a 13/03/2006 no Departamento de Zootecnia da Universidade Federal de Santa Maria, localizado na latitude de $29^{\circ} 43^{\prime}$ Sul e longitude $53^{\circ} 42^{\prime}$ Oeste, na Depressão Central do Rio Grande do Sul.

Foram utilizados 16 tourinhos contemporâneos, desmamados precocemente, mestiços Charolês-Nelore. Os animais apresentaram ao início do período experimental idade e peso vivo (PV) médio de 9,3 meses e 192,44 kg, respectivamente. Os animais foram confinados individualmente em baias cobertas de $12 \mathrm{~m}^{2}$, pavimentadas com concreto e providas de comedouros individualizados e bebedouros regulados com torneira-bóia, e alimentados com dietas constituídas por $22,40,59$ ou $79 \%$ de concentrado.

O volumoso utilizado foi silagem de milho do híbrido BRS - 3150, com 23\% de grãos na MS ensilada, cortado a $20 \mathrm{~cm}$ do solo. A dieta (Tabela 1) foi calculada para ser isoprotéica, com $12 \%$ de proteína bruta $(\mathrm{PB})$, estimando-se consumo de $3 \mathrm{~kg}$ de MS/100 kg de PV.

À medida que os animais de cada tratamento atingiram o peso vivo médio pré-determinado $(400 \mathrm{~kg})$, foram abatidos em frigorífico comercial a $54 \mathrm{~km}$ distante do confinamento. Durante o abate, todas as partes do corpo dos bovinos foram separadas e pesadas individualmente e consistiram de: conjunto de componentes externos - cabeça, patas, orelhas, chifres (quando presentes), vassoura da cauda, couro e testículos; conjunto de órgãos vitais - pulmão, fígado, rins, coração e baço; conjunto de gorduras internas: gordura de toalete, inguinal, renal, coração, retículo-rúmen e intestino (gordura do intestino delgado + gordura do intestino grosso); conjunto do trato digestivo vazio rúmen-retículo, omaso, abomaso, intestino grosso + intestino delgado vazio; e sangue.

Antes de ser encaminhadas à câmara de resfriamento, as duas meia-carcaças foram identificadas e pesadas para determinação do peso de carcaça quente. O peso de corpo vazio (PCVZ) foi obtido pelo somatório do peso de carcaça quente, sangue e de todos os componentes agrupados conforme citado anteriormente.

Os dados foram submetidos à análise de normalidade de distribuição pelo teste de Shapiro-Wilk e quanto à homogeneidade da variância, pelo teste de Bartlett, consi-

Tabela 1 - Composição das dietas experimentais

\begin{tabular}{lrrrr}
\hline Ingrediente (\% MS) & \multicolumn{4}{c}{ Nível de concentrado $(\%)$} \\
\cline { 2 - 5 } & \multicolumn{1}{c}{22} & \multicolumn{1}{c}{40} & \multicolumn{1}{c}{59} & 79 \\
\hline Silagem milho & 78,00 & 60,00 & 41,00 & 21,00 \\
Milho grão & 5,91 & 9,43 & 29,32 & 49,15 \\
Farelo soja & 3,52 & 4,11 & 2,57 & 0,32 \\
Farelo trigo & 10,57 & 24,27 & 24,79 & 26,97 \\
Calcário calcítico & 0,92 & 1,46 & 1,63 & 1,92 \\
NaCl & 0,33 & 0,32 & 0,32 & 0,32 \\
Uréia & 0,51 & 0,37 & 0,32 & 0,27 \\
Monensina sódica & 0,09 & 0,05 & 0,03 & 0,04 \\
Sulfato de amônio & 0,13 & 0,05 & 0,03 & 0,02 \\
Nutriente (\%MS) & & & & \\
Proteína bruta, & 11,20 & 12,50 & 12,10 & 11,80 \\
Energia digestível, Mcal/kg & 2,87 & 2,94 & 3,11 & 3,27 \\
FDN & 48,00 & 43,80 & 38,10 & 28,70 \\
\hline
\end{tabular}


derando o nível de 5\% de significância. Os resultados foram analisados estatisticamente por análise de variância utilizando-se o procedimento GLM, com auxílio do programa estatístico SAS (1997). Foi realizado também teste de correlação e regressão polinomial. O valor do coeficiente de determinação foi calculado a partir da soma de quadrados da regressão considerada significativa dividida pela soma de quadrados de tratamento.

Os dados foram analisados acordo com o seguinte modelo matemático geral:

$$
\mathrm{Y}_{\mathrm{ij}}=\mu+\mathrm{T}_{\mathrm{i}}+\varepsilon_{\mathrm{ij}}
$$

em que: $\mathrm{Y}_{\mathrm{ij}}=$ variáveis dependentes; $\mu=$ média de todas as observações; $T_{i}=$ efeito dos tratamentos; e $\varepsilon_{i j}=$ erro experimental residual (erro b). No estudo da regressão polinomial, utilizou-se o seguinte modelo:

$$
Y_{i j k}=\beta_{0}+\beta_{1} X_{i}+\beta_{2} X_{i}^{2}+\alpha_{i j k}+\varepsilon_{i j k},
$$

no qual $Y_{\mathrm{ijk}}=$ variáveis dependentes; $\beta$ = coeficientes de regressão; $\mathrm{X}_{\mathrm{ijk}}=$ variáveis independentes; $\alpha_{\mathrm{ijk}}=$ desvios da regressão; e $\varepsilon_{\mathrm{ijk}}=$ erro aleatório residual.

\section{Resultados e Discussão}

Os resultados referentes ao desempenho animal, consumo de nutrientes, características da carcaça e carne são encontrados nos trabalhos de Missio et al. (2007, 2009). Neste trabalho, a idade de abate diminuiu com o aumento do nível de concentrado (Tabela 2), o que está relacionado ao maior ganho de peso vivo dos animais alimentados com proporções superiores de concentrado. Por outro lado, a idade inicial, o peso vivo e o peso de abate foram similares entre os tratamentos, já que foram previamente estipulados.

$\mathrm{O}$ aumento de concentrado na dieta não influenciou ( $P>0,05)$ o PCVZ, RCQ e RCF, em virtude da semelhança do peso de abate e as variações nos demais componentes do corpo vazio. Signoretti et al. (1999), trabalhando com bovinos leiteiros abatidos aos 190 e $300 \mathrm{~kg}$, alimentados com níveis crescentes de concentrado na dieta $(45,60,75$ e 90\%) e Silva et al. (2002), ao abaterem novilhos Nelore aos $450 \mathrm{~kg}$, alimentados com 20, 40, 60 e $80 \%$ de concentrado, verificaram diminuição do PCVZ. Esses autores associaram o fato ao aumento do conteúdo gastrintestinal, mas isso não foi verificado neste estudo. Quanto ao rendimento de carcaça ajustado para o PCVZ, Ferreira et al. (2000) não verificaram diferenças para os níveis 25,$0 ; 37,5 ; 50,0 ; 62,5$ e $75,0 \%$ de concentrado na dieta. O comportamento desta variável foi atribuído pelos autores à equivalência causada pelas variações do peso do conteúdo do trato gastrintestinal (CTGI), órgãos internos e gordura interna. Silva et al. (2002), no entanto, verificaram aumento linear para essa característica, que foi associado à diminuição linear do CTGI. Segundo Petit et al. (1994), quando o peso de abate e o período de jejum são pré-determinados, o rendimento de carcaça parece não ser alterado.

Os pesos absolutos de orelha, cabeça, patas, vassoura da cauda, couro e testículo não foram influenciados $(\mathrm{P}>0,05)$ pelo aumento de concentrado na dieta, o mesmo acontecendo com os pesos de orelhas e vassoura da cauda ajustados para PCVZ e peso de abate (Tabela 3 ). O peso de cabeça ajustado para peso de abate não foi influenciado $(\mathrm{P}>0,05)$ pelo aumento do nível de concentrado, porém esta variável ajustada para PCVZ diminuiu linearmente, reflexo do aumento de outros componentes corporais, como a gordura interna $(r=-0,65 ; P=0,007)$. Essa correlação comprova efeito indireto da gordura interna em relação ao peso relativo da cabeça, visto que a principal contribuição nutricional do aumento na proporção de concentrado nas dietas (isoprotéicas) foi representada pelo aumento de energia, que foi depositada na forma de gordura no tecido muscular, nas vísceras e nos órgãos em detrimento ao depósito de gordura na cabeça, favorecendo a diminuição do peso proporcional da cabeça, fato observado durante o abate dos animais, quando se observou que a quantidade de

Tabela 2 - Idade inicial e de abate, peso vivo inicial e de abate, peso de corpo vazio e rendimento de carcaça quente e fria em relação ao

\begin{tabular}{|c|c|c|c|c|c|c|c|}
\hline \multirow[t]{2}{*}{ Variável } & \multicolumn{4}{|c|}{ Nível de concentrado (\%) } & \multirow[t]{2}{*}{ Média } & \multirow[t]{2}{*}{ Erro-padrão } & \multirow[t]{2}{*}{ Probabilidade } \\
\hline & 22 & 40 & 59 & 79 & & & \\
\hline Idade inicial, meses & 9,45 & 8,85 & 9,52 & 9,45 & 9,32 & 0,40 & 0,610 \\
\hline Idade de abate, meses ${ }^{1}$ & 16,60 & 15,00 & 14,80 & 14,80 & 15,28 & 0,38 & 0,010 \\
\hline Peso vivo inicial, $\mathrm{kg}$ & 191,25 & 187,00 & 197,50 & 194,00 & 192,44 & 15,76 & 0,970 \\
\hline Peso de abtae, $\mathrm{kg}$ & 400,75 & 407,25 & 392,75 & 394,75 & 398,88 & 30,21 & 0,990 \\
\hline Peso de corpo vazio (PCVZ), $\mathrm{kg}$ & 354,17 & 362,88 & 354,96 & 357,86 & 357,47 & 25,19 & 0,994 \\
\hline $\begin{array}{l}\text { Rendimento de carcaça quente, } \\
\mathrm{kg} / 100 \mathrm{~kg} \text { de PCVZ }\end{array}$ & 65,91 & 65,08 & 64,97 & 64,25 & 65,05 & 0,69 & 0,464 \\
\hline $\begin{array}{l}\text { Rendimento de carcaça fria, } \\
\mathrm{kg} / 100 \mathrm{~kg} \text { de PCVZ }\end{array}$ & 64,41 & 63,53 & 63,55 & 62,79 & 63,57 & 0,76 & 0,536 \\
\hline
\end{tabular}
peso de corpo vazio de tourinhos superjovens terminados em confinamento com dietas com diversos níveis de concentrado

${ }^{1}$ IDA $=16,79-0,0302 \mathrm{C}, \mathrm{R}^{2}=0,51, \mathrm{CV}=5,03 ; \mathrm{C}=$ nível de concentrado na dieta

Adaptado de Missio et al. (2008a) 
Tabela 3 - Peso dos componentes externos de tourinhos superjovens terminados em confinamento com dietas com diversos níveis de concentrado

\begin{tabular}{|c|c|c|c|c|c|c|c|}
\hline \multirow[t]{2}{*}{ Variável } & \multicolumn{4}{|c|}{ Nível de concentrado (\%) } & \multirow[t]{2}{*}{ Média } & \multirow[t]{2}{*}{ Erro-padrão } & \multirow[t]{2}{*}{ Probabilidade } \\
\hline & 22 & 40 & 59 & 79 & & & \\
\hline Orelhas, kg & 0,77 & 0,69 & 0,67 & 0,65 & 0,70 & 0,06 & 0,548 \\
\hline Orelhas, \% PCVZ & 0,22 & 0,19 & 0,19 & 0,18 & 0,20 & 0,01 & 0,387 \\
\hline Orelhas, \% PA & 0,19 & 0,17 & 0,17 & 0,16 & 0,18 & 0,01 & 0,495 \\
\hline Cabeça, kg & 13,72 & 13,72 & 12,69 & 12,52 & 13,16 & 0,97 & 0,758 \\
\hline Cabeça, \% PCVZ 1 & 3,91 & 3,77 & 3,60 & 3,49 & 3,69 & 0,13 & 0,030 \\
\hline Cabeça, \% PA & 3,45 & 3,37 & 3,25 & 3,17 & 3,31 & 0,12 & 0,187 \\
\hline Patas, kg & 6,89 & 7,36 & 7,72 & 7,57 & 7,38 & 0,66 & 0,609 \\
\hline Patas, \% PCVZ ${ }^{2}$ & 1,95 & 0,02 & 2,15 & 2,11 & 2,06 & 0,07 & 0,049 \\
\hline Patas, \% $\mathrm{PA}^{3}$ & 1,72 & 1,81 & 1,95 & 1,92 & 1,85 & 0,06 & 0,016 \\
\hline Vassoura cauda, $\mathrm{kg}$ & 0,34 & 0,20 & 0,25 & 0,33 & 0,28 & 0,04 & 0,322 \\
\hline Vassoura cauda, \% PCVZ & 0,10 & 0,06 & 0,08 & 0,09 & 0,08 & 0,01 & 0,507 \\
\hline Vassoura cauda, \% PA & 0,08 & 0,05 & 0,07 & 0,08 & 0,07 & 0,01 & 0,512 \\
\hline Couro, kg & 43,08 & 42,76 & 39,30 & 41,62 & 41,69 & 2,50 & 0,194 \\
\hline Couro, \% PCVZ & 12,27 & 11,76 & 11,16 & 11,73 & 11,73 & 0,69 & 0,847 \\
\hline Couro, \% PA & 10,81 & 10,53 & 10,08 & 10,65 & 10,52 & 0,61 & 0,925 \\
\hline Testículos, kg & 0,39 & 0,46 & 0,43 & 0,55 & 0,46 & 0,07 & 0,592 \\
\hline Testículos, \% PCVZ & 0,11 & 0,13 & 0,12 & 0,16 & 0,13 & 0,02 & 0,286 \\
\hline Testículos, \% PA & 0,10 & 0,11 & 0,11 & 0,14 & 0,12 & 0,02 & 0,264 \\
\hline
\end{tabular}

${ }^{1}$ Cabeça, \% PCVZ $=4,064-0,00744 \mathrm{C}, \mathrm{CV}=7,105, \mathrm{R}^{2}=0,61$

2 Patas, \% PCVZ $=1,898+0,00325 \mathrm{C}, \mathrm{CV}=6,221, \mathrm{R}^{2}=0,80$

${ }^{3}$ Patas, $\% \mathrm{PA}=1,657+0,00383 \mathrm{C}, \mathrm{CV}=6,476, \mathrm{R}^{2}=0,85$

$\mathrm{C}=$ nível de concentrado na dieta.

gordura na cabeça dos animais foi baixa, o que está relacionado à composição tecidual da cabeça, principalmente osso e carne magra.

O peso de patas ajustado para o PCVZ e peso de abate aumentou linearmente com o nível de concentrado na dieta, concordando com as observações de Clementino et al. (2007). A maior porcentagem de patas está relacionada ao crescimento precoce do tecido ósseo e à redução da idade de abate com a elevação do nível de concentrado na dieta. No trabalho de Ribeiro et al. (2001), o peso relativo de patas diminuiu com o aumento da idade do animal, resultado do perfil de crescimento dos tecidos, primeiro osso, depois músculos e por último gordura.

Os componentes externos da carcaça não representam remuneração ao produtor, mas são importantes porque exercem influência no rendimento de carcaça. Carvalho et al. (2003) citam que menores participações destes componentes podem aumentar o rendimento de carcaça. Entre os componentes externos de maior importância, destacam-se a cabeça e o couro que é comercializado in natura a curtumes que o beneficiam para a indústria calçadista e de vestuário. A cabeça é desossada e a carne destinada principalmente à produção e comercialização na forma decarne moída, produção de embutidos e alimentos processados.

Os órgãos vitais, como fígado, rins, baço e coração também não constituem renda ao pecuarista, em comercializações via rendimento de carcaça, mas representam para os frigoríficos (Tabela 4). De modo geral, não existem estudos que comprovem a lucratividade real dos sistemas frigoríficos, entretanto, sabe-se que parte das despesas operacionais é custeada com dividendos provenientes da comercialização de órgãos, couros, carnes da cabeça e demais resíduos destinados à produção de ração animal.

O aumento do nível de concentrado na dieta não alterou $(\mathrm{P}>0,05)$ os pesos absolutos de coração e pulmões. Segundo Perón et al. (1993), essas variáveis mantêm sua integridade por terem prioridade na utilização de nutrientes, independentemente do nível de alimentação. Conforme equação de regressão neste estudo, quando o peso de coração foi ajustado para o PCVZ (CORPCVZ) e peso de abate (CORPA) verificaram-se aumentos lineares com a elevação do nível de concentrado na dieta, os quais apresentaram correlação positiva com o consumo de matéria seca $(\mathrm{r}=0,54 ; \mathrm{P}=0,0299$ e $\mathrm{r}=0,54 ; \mathrm{P}=0,0315$, respectivamente) e energia digestível $(\mathrm{r}=0,62 ; \mathrm{P}=0,0112$ e $\mathrm{r}=0,64 ; \mathrm{P}=0,0076$, respectivamente $)$. Ribeiro et al. (2001) avaliaram o efeito de níveis crescentes de concentrado para bovinos de raça leiteira abatidos aos $194 \mathrm{~kg}$ com idade ao abate variando entre 5,7 e 6,6 meses e verificaram que o peso do coração foi melhor ajustado à equação de regressão quadrática positiva e associaram o aumento dos órgãos internos ao acréscimo do consumo de energia e ao aumento do peso de sangue (Tabela 5).

Neste estudo, quando testada regressão do CORPCVZ em relação ao consumo de energia digestível (CED) verificou-se aumento linear desta variável com o aumento da 
Tabela 4 - Pesos dos órgãos de tourinhos superjovens terminados em confinamento com dietas com diversos níveis de concentrado

\begin{tabular}{|c|c|c|c|c|c|c|c|}
\hline \multirow[t]{2}{*}{ Variável } & \multicolumn{4}{|c|}{ Nível de concentrado $(\%)$} & \multirow[t]{2}{*}{ Média } & \multirow[t]{2}{*}{ Erro-padrão } & \multirow[t]{2}{*}{ Probabilidade } \\
\hline & 22 & 40 & 59 & 79 & & & \\
\hline Coração, kg & 1,40 & 1,53 & 1,64 & 1,59 & 1,54 & 0,16 & 0,336 \\
\hline Coração, \% $\mathrm{PCVZ}^{1}$ & 0,10 & 0,06 & 0,10 & 0,09 & 0,43 & 0,02 & 0,038 \\
\hline Coração, \% $\mathrm{PA}^{2}$ & 0,35 & 0,38 & 0,42 & 0,40 & 0,38 & 0,02 & 0,012 \\
\hline Pulmões, kg & 3,73 & 3,79 & 3,56 & 3,73 & 3,70 & 0,22 & 0,891 \\
\hline Pulmões, \% PCVZ & 1,06 & 1,04 & 1,02 & 1,05 & 1,04 & 0,05 & 0,939 \\
\hline Pulmões, \% PA & 1,06 & 1,26 & 1,21 & 1,17 & 0,94 & 0,08 & 0,964 \\
\hline Fígado, kg & 4,25 & 5,04 & 4,75 & 4,72 & 4,67 & 0,43 & 0,635 \\
\hline Fígado, \% PCVZ & 1,20 & 1,41 & 1,34 & 1,29 & 1,31 & 0,08 & 0,346 \\
\hline Fígado, \% PA & 1,06 & 1,26 & 1,21 & 1,17 & 1,18 & 0,08 & 0,318 \\
\hline Rins, kg & 0,74 & 0,74 & 0,72 & 0,79 & 0,75 & 0,07 & 0,906 \\
\hline Rins, \% PCVZ & 0,21 & 0,20 & 0,20 & 0,22 & 0,21 & 0,01 & 0,635 \\
\hline Rins, \% PA & 0,18 & 0,18 & 0,18 & 0,20 & 0,19 & 0,01 & 0,495 \\
\hline Baço, kg & 1,21 & 1,20 & 1,36 & 1,50 & 1,32 & 0,14 & 0,080 \\
\hline Baço, \% PCVZ & 0,35 & 0,33 & 0,38 & 0,42 & 0,37 & 0,03 & 0,069 \\
\hline Baço, $\% \mathrm{PA}^{3}$ & 0,31 & 0,30 & 0,35 & 0,38 & 0,33 & 0,03 & 0,049 \\
\hline
\end{tabular}

${ }^{1}$ Coração, $\% \mathrm{PCVZ}=0,378+0,001 \mathrm{C}, \mathrm{CV}=8,777, \mathrm{R}^{2}=0,63$.

2 Coração, \% PA=0,330+0,0011C, CV $=8,401, \mathrm{R}^{2}=0,81$.

${ }^{3}$ Baco, \% PA=0,263+0,0014C, CV $=16,475, \mathrm{R}^{2}=0,61$

$\mathrm{C}=$ nível de concentrado na dieta.

Tabela 5 - Equações de regressão para peso de coração ajustado para o peso de corpo vazio (CORPCVZ), peso de baço ajustado para o peso de abate (BAÇOPA) em relação ao consumo de energia digestível (CED) e quantidade de gordura do abomaso (GA)

\begin{tabular}{ccc}
\hline Equação de regressão & $\mathrm{R}^{2}$ & $\mathrm{P}$ \\
\hline CORPCVZ $=0,27+0,0058 \mathrm{CED}$ & 0,42 & 0,011 \\
$\mathrm{BAÇOPA}=0,472+0,031 \mathrm{CED}$ & 0,31 & 0,032 \\
$\mathrm{BAÇOPA}=0,461-0,094 \mathrm{GA}$ & 0,83 & 0,004 \\
\hline
\end{tabular}

ingestão de energia (Tabela 5). Apesar de significativo, o coeficiente de determinação para a regressão foi baixo, demonstrando que o modelo não se ajustou adequadamente aos dados e inferindo que o CED teve pouca influência na alteração do CORPCVZ. Contudo, a partir de análise de regressão múltipla verificou-se que a variação dos pesos relativos do coração foi resultado da associação de efeitos $(\mathrm{P}<0,05)$ de diversos componentes do corpo vazio como o peso de intestino e gordura de toalete, idade de abate, peso de abate, consumo de energia e ganho de peso vivo diário.

Os pesos absolutos e relativos do fígado, dos rins e do baço, exceto o peso de baço ajustado para peso ao abate, não foram influenciados $(\mathrm{P}>0,05)$ pelo acréscimo de concentrado na dieta. Esses resultados não eram esperados, pois, segundo Ferrell et al. (1976), o tamanho de fígado, rins e baço aumenta quando o consumo de nutrientes melhora, especialmente energia e proteína, que participam ativamente no metabolismo destes nutrientes. Por outro lado, Silva et al. (2002), avaliando a biometria dos órgãos internos de bovinos Nelore não-castrados, abatidos aos 360 e $450 \mathrm{~kg}$, sob níveis de concentrado na dieta bem semelhantes, não verificaram alteração no tamanho de fígado, rins, baço e demais órgãos. Esses autores atribuíram os resultados à qualidade superior do volumoso utilizado, o qual teria fornecido, mesmo nas dietas com maior proporção de volumoso, condições energéticas suficientes para o máximo desenvolvimento dos órgãos. Além disso, a ausência de diferenças entre os níveis de concentrado para peso de fígado e baço neste estudo pode estar relacionada ao ímpeto de crescimento destes órgãos, que alcançam sua maturidade mais tarde que pulmões e coração (Jorge \& Fontes, 2001).

O peso de baço ajustado para peso de abate (BAÇOPA) aumentou linearmente com o acréscimo de concentrado na dieta, quando testada a regressão do BAÇOPA em função do consumo de energia (Tabela 5). Embora significativo, o coeficiente de determinação foi baixo, demonstrando que o CED não foi a principal causa do aumento do BAÇOPA. A explicação para o aumento do BAÇOPA está principalmente na diminuição da gordura do abomaso, visto que a regressão do BAÇOPA em função do peso da gordura do abomaso foi significativa e com alto coeficiente de determinação (Tabela 5).

De modo geral, resultados obtidos em diferentes pesquisas sobre a biometria de órgãos internos de bovinos são contrastantes. A explicação para estas divergências entre resultados estaria associada às diferenças entre a fase de desenvolvimento do animal em que foram feitas as mensurações do tamanho dos órgãos, uma vez que, segundo verificações de alguns autores (Almeida et al., 2001; Jorge \& Fontes, 2001), os órgãos vitais, assim como os tecidos do corpo do animal apresentam taxas máximas de crescimento distintas em momentos diferentes. Ainda segundo Black (1989), existem diferenças entre genótipos 
quanto ao modelo de desenvolvimento ou velocidade de formação dos órgãos e dos tecidos que constituem a massa do corpo. Esta velocidade de desenvolvimento pode também ser afetada pelo tamanho do corpo adulto e hormônios (Jorge \& Fontes, 2001), pela idade e outras causas ambientais (Coleman et al., 1993).

O peso absoluto e os pesos relativos do rúmen-retículo não foram alterados pelo aumento do nível de concentrado na dieta (Tabela 6). Ferreira et al. (2000) e Véras et al. (2001) verificaram comportamento quadrático para o peso de retículo-rúmen com o aumento de concentrado na dieta e obtiveram os valores mínimos com 43,8 e $51,7 \%$ de concentrado, respectivamente.

O comportamento quadrático para peso de retículorúmen foi associado no estudo de Ferreira et al. (2000) ao consumo de matéria seca, o que não foi evidenciado neste estudo. Segundo Rohr \& Daenicke (1984) o conteúdo do TGI é proporcional ao tamanho das partículas do alimento e inversamente proporcional à digestibilidade da forragem. Macitelli et al. (2005) também verificaram que o retículorúmen foi maior em animais alimentados com silagem de cana-de-açúcar em relação aos alimentados com silagem de milho e pastagem de Brachiaria brizantha. Esses autores atribuíram esse aumento ao maior tamanho de partícula da silagem de cana em relação aos demais volumosos, já que, na dieta com cana, o teor de fibra em detergente neutro (FDN) foi menor.

O aumento do nível de concentrado na dieta não influenciou $(\mathrm{P}>0,05)$ o peso absoluto de omaso. Quando essa variável foi expressa em porcentagem ao PCVZ diminuiu $0,006 \%$ para cada porcentagem de aumento no nível de concentrado na dieta, o que está de acordo com os dados obtidos por Ferreira et al. (2000). Segundo Van Soest (1994), dietas com altos níveis de concentrado provocam involução do omaso. De outra maneira, quando expresso em porcentagem do peso de abate, a participação do omaso foi melhor explicada por equação de regressão quadrática, comportamento relacionado às variações no peso de abomaso $(\mathrm{r}=0,87 ; \mathrm{P}<0,0001)$, gordura do rúmen $(\mathrm{r}=0,74 ; \mathrm{P}=0,001)$, intestino $(\mathrm{r}=0,68 ; \mathrm{P}=0,0035)$ e gordura do intestino $(\mathrm{r}=-0,55 ; \mathrm{P}=0,0279)$.

O peso de abomaso, nas três formas em que foi expresso, ajustou-se melhor à equação de regressão quadrática. Os mínimos valores obtidos pela equação de regressão foram para dietas com 68,0;66,7 e 69,2\% de concentrado, para o peso em kg, \% PCVZ e PA, respectivamente. Segundo alguns autores (Strozinski et al., 1971; Warner et al., 1956, citados por Lucci, 1989), o volume do abomaso e sua musculatura crescem em proporções aproximadas aos ganhos de peso do corpo, de maneira independente da dieta.

$\mathrm{O}$ aumento da proporção de concentrado na dieta ocasionou aumento de $0,07 \mathrm{~kg}, 0,02$ e $0,02 \%$ do peso de intestino, em kg, relação ao peso de corpo vazio e peso de abate, respectivamente, concordando com os resultados obtidos por Ferreira et al. (2000). O aumento do tamanho do intestino pode estar relacionado à maior atividade metabólica intestinal, decorrente da elevação da quantidade de milho moído nas dietas com elevados níveis de concentrado (Tabela 1). Segundo Kozloski (2001), quando dietas são

Tabela 6 - Pesos de rúmen-retículo, omaso, abomaso e intestinos de tourinhos superjovens terminados em confinamento com dietas com diversos níveis de concentrado

\begin{tabular}{|c|c|c|c|c|c|c|c|}
\hline \multirow[t]{2}{*}{ Variável } & \multicolumn{4}{|c|}{ Nível de concentrado (\%) } & \multirow[t]{2}{*}{ Média } & \multirow[t]{2}{*}{ Erro-padrão } & \multirow[t]{2}{*}{ Probabilidade } \\
\hline & 22 & 40 & 59 & 79 & & & \\
\hline Rúmen-retículo, kg & 6,05 & 6,36 & 5,89 & 5,81 & 6,03 & 0,50 & 0,871 \\
\hline Rúmen-retículo, \% PCVZ & 1,72 & 1,75 & 1,66 & 1,61 & 1,68 & 0,07 & 0,304 \\
\hline Rúmen-retículo, \% PA & 1,51 & 1,57 & 1,50 & 1,46 & 1,51 & 0,05 & 0,476 \\
\hline Omaso, kg & 4,68 & 4,96 & 4,26 & 3,74 & 4,41 & 0,45 & 0,291 \\
\hline Omaso, $\% \mathrm{PCVZ}^{1}$ & 1,36 & 1,36 & 1,19 & 1,04 & 1,24 & 0,10 & 0,022 \\
\hline Omaso, $\% \mathrm{PA}^{2}$ & 0,30 & 0,37 & 0,61 & 0,51 & 0,45 & 0,03 & 0,040 \\
\hline Abomaso, $\mathrm{kg}^{3}$ & 1,21 & 1,51 & 2,38 & 2,00 & 1,78 & 0,16 & 0,006 \\
\hline Abomaso, \% $\mathrm{PCVZ}^{4}$ & 0,34 & 0,42 & 0,68 & 0,56 & 0,50 & 0,04 & 0,045 \\
\hline Abomaso, $\% \mathrm{PA}^{5}$ & 0,30 & 0,37 & 0,61 & 0,51 & 0,45 & 0,03 & 0,040 \\
\hline Intestinos, $\mathrm{kg}^{6}$ & 3,42 & 4,09 & 6,54 & 7,08 & 5,28 & 0,53 & 0,0001 \\
\hline Intestinos, $\% \mathrm{PCVZ}^{7}$ & 0,97 & 1,13 & 1,85 & 2,00 & 1,49 & 0,12 & 0,0001 \\
\hline Intestinos, $\% \mathrm{PA}^{8}$ & 0,86 & 1,01 & 1,87 & 1,82 & 1,34 & 0,11 & 0,0001 \\
\hline
\end{tabular}

1 OMA, \% PCVZ $=1,54-0,006 \mathrm{C}, \mathrm{CV}=15,909, \mathrm{R}^{2}=0,90$.

2 OMA, \% PA $=-0,0560+0,018 \mathrm{C}-0,00013 \mathrm{C}^{2}, \mathrm{CV}=18,931, \mathrm{R}^{2}=0,79$

$3 \mathrm{ABO}, \mathrm{kg}=-0,141+0,068 \mathrm{C}-0,00051 \mathrm{C}^{2}, \mathrm{CV}=22,905, \mathrm{R}^{2}=0,73$.

${ }^{4} \mathrm{ABO}, \% \mathrm{PCVZ}=-0,048+0,02 \mathrm{C}-0,00015 \mathrm{C}^{2}, \mathrm{CV}=19,340, \mathrm{R}^{2}=0,78$

$5 \mathrm{ABO} \% \mathrm{PA}=-0,056+0,018 \mathrm{C}-0,00013 \mathrm{C}^{2}, \mathrm{CV}=18,930, \mathrm{R}^{2}=0,78$

${ }^{6}$ Intestinos , $\mathrm{kg}=1,759+0,07 \mathrm{C}, \mathrm{CV}=20,104, \mathrm{R}^{2}=0,92$.

${ }^{7}$ Intestinos , \% PCVZ $=0,487+0,02 \mathrm{C}, \mathrm{CV}=19,083, \mathrm{R}^{2}=0,86$.

${ }^{8}$ Intestinos, \% PA $=0,409+0,02 \mathrm{C}, \mathrm{CV}=19,351, \mathrm{R}^{2}=0,86$

$\mathrm{C}=$ nível de concentrado na dieta. 
constituídas por elevadas proporções de cereais, principalmente milho ou sorgo, quantidades significativas de amido podem passar pelo rúmen sem serem fermentadas e são digeridas nos intestinos. Neste estudo, foi observado visualmente que, à medida que se elevou o nível de concentrado na dieta aumentou a quantidade de milho nas fezes, indicando aumento da digestão intestinal. Além disso, verificou-se associação positiva entre o peso de intestino e o consumo de matéria seca e energia digestível $(\mathrm{r}=0,58$; $\mathrm{P}=0,0199$ e $\mathrm{r}=0,69 ; \mathrm{P}=0,0029$, respectivamente).

Os pesos absolutos e relativos para gordura inguinal e intestino não foram alterados $(\mathrm{P}>0,05)$ pelo acréscimo do nível de concentrado na dieta (Tabela 7). Da mesma forma, o peso absoluto de gordura do coração não apresentou variação significativa nos diferentes níveis de concentrado na dieta, no entanto, quando o valor foi expresso em relação ao PCVZ e peso de abate, a equação de regressão cúbica foi melhor ajustada, comportamento associado às variações dos demais componentes avaliados.

O aumento do concentrado na dieta promoveu aumentos lineares na deposição de gordura de toalete (Tabela 7), o que está associado ao aumento no consumo de energia $(\mathrm{r}=0,89 ; \mathrm{P}<0,0001)$. O toalete representa o excesso de gordura interna e externa retirado da carcaça após o resfriamento e esse procedimento é constantemente motivo de desentendimentos entre produtores e frigoríficos, visto que diminui o peso da carcaça e a remuneração a ser obtida por animal comercializado.

O nível de concentrado na dieta influenciou $(\mathrm{P}<0,05)$ a deposição de gordura no rúmen e no abomaso, mas não foi verificado efeito significativo sobre a deposição de gordura nos intestinos (Tabela 8). A falta de variação $(\mathrm{P}>0,05)$ para os pesos de gordura intestinal pode estar caracterizando perfil de deposição mais tardio desta gordura em relação à intermuscular e subcutânea.

Os pesos da gordura ruminal e abomasal, nas formas como foram expressos, mostraram-se lineares crescentes e decrescentes, respectivamente, com a elevação da proporção de concentrado na dieta. $O$ peso da gordura do rúmen foi positivamente correlacionado ao consumo de energia $(\mathrm{r}=0,83 ; \mathrm{P}<0,0001)$, o que justifica seu aumento. Por outro lado, o peso da gordura abomasal foi negativamente correlacionado ao peso de intestinos $(\mathrm{r}=-0,59 ; \mathrm{P}=0,0189)$ e CTGI ajustado para PCV $(r=-0,61 ; P=0,0120)$, assim, a

Tabela 7 - Pesos e rendimentos de gordura em tourinhos superjovens terminados em confinamento com dietas com diversos níveis de concentrado

\begin{tabular}{|c|c|c|c|c|c|c|c|}
\hline \multirow[t]{2}{*}{ Gordura } & \multicolumn{4}{|c|}{ Nível de concentrado (\%) } & \multirow[t]{2}{*}{ Média } & \multirow[t]{2}{*}{ Erro-padrão } & \multirow[t]{2}{*}{ Probabilidade } \\
\hline & 22 & 40 & 59 & 79 & & & \\
\hline Inguinal, kg & 2,46 & 2,46 & 2,58 & 2,62 & 2,53 & 0,17 & 0,862 \\
\hline Inguinal, \% PCVZ & 0,70 & 0,67 & 0,73 & 0,75 & 0,71 & 0,07 & 0,849 \\
\hline Inguinal, \% PA & 0,61 & 0,60 & 0,66 & 0,68 & 0,64 & 0,06 & 0,745 \\
\hline Coração, kg & 0,38 & 0,36 & 0,58 & 0,51 & 0,46 & 0,08 & 0,182 \\
\hline Coração, \% PCVZ ${ }^{1}$ & 0,40 & 0,51 & 0,91 & 0,95 & 0,13 & 0,08 & 0,048 \\
\hline Coração, \% $\mathrm{PA}^{2}$ & 0,35 & 0,46 & 0,82 & 0,86 & 0,12 & 0,07 & 0,048 \\
\hline Renal, kg & 3,54 & 5,61 & 4,65 & 5,24 & 4,76 & 0,53 & 0,083 \\
\hline Renal, \% PCVZ & 1,01 & 1,55 & 1,31 & 1,48 & 1,34 & 0,16 & 0,145 \\
\hline Renal, \% PA & 0,89 & 1,39 & 1,18 & 1,34 & 1,20 & 0,15 & 0,127 \\
\hline Toalete, $\mathrm{kg}^{3}$ & 2,14 & 3,28 & 3,56 & 3,91 & 3,22 & 0,54 & 0,043 \\
\hline Toalete, \% $\mathrm{PCVZ}^{4}$ & 0,57 & 0,90 & 0,99 & 1,08 & 0,88 & 0,10 & 0,004 \\
\hline Toalete, $\% \mathrm{PA}^{5}$ & 0,57 & 0,90 & 0,99 & 1,08 & 0,79 & 0,10 & 0,002 \\
\hline Rúmen, $\mathrm{kg}^{6}$ & 1,45 & 1,86 & 3,19 & 3,41 & 2,48 & 0,32 & 0,0003 \\
\hline Rúmen, \% $\mathrm{PCVZ}^{7}$ & 0,40 & 0,51 & 0,91 & 0,95 & 0,69 & 0,08 & 0,0001 \\
\hline Rúmen, \% $\mathrm{PA}^{8}$ & 0,35 & 0,46 & 0,82 & 0,86 & 0,62 & 0,07 & 0,0001 \\
\hline Abomaso, $\mathrm{kg}^{9}$ & 1,51 & 1,79 & 1,22 & 0,95 & 1,37 & 0,12 & 0,014 \\
\hline Abomaso, $\% \mathrm{PCVZ}^{10}$ & 0,43 & 0,50 & 0,34 & 0,27 & 0,38 & 0,04 & 0,010 \\
\hline Abomaso, $\% \mathrm{PA}^{11}$ & 0,38 & 0,45 & 0,31 & 0,25 & 034 & 0,04 & 0,016 \\
\hline Intestinal, $\mathrm{kg}$ & 6,78 & 7,26 & 5,31 & 6,25 & 6,40 & 0,74 & 0,330 \\
\hline Intestinal, $\% \mathrm{PCVZ}$ & 1,94 & 2,02 & 1,50 & 1,72 & 1,80 & 0,16 & 0,151 \\
\hline Intestinal, \% PA & 1,72 & 1,81 & 1,36 & 1,56 & 1,61 & 0,14 & 0,197 \\
\hline
\end{tabular}

$1 \% \mathrm{PCVZ}=0,45-0,028 \mathrm{C}+0,00065 \mathrm{C}^{2}-0,000044 \mathrm{C}^{3}, \mathrm{CV}=28,256, \mathrm{R}^{2}=0,96$.

$2 \% \mathrm{PA}=0,39-0,024 \mathrm{C}+0,00057 \mathrm{C}^{2}-0,000039 \mathrm{C}^{3}, \mathrm{CV}=27,836, \mathrm{R}^{2}=0,96$

${ }^{3} \mathrm{~kg}=1,761+0,029 \mathrm{C}, \mathrm{CV}=34,660, \mathrm{R}^{2}=0,57$.

$4 \% \mathrm{PCVZ}=0,457+0,0086 \mathrm{C}, \mathrm{CV}=21,712, \mathrm{R}^{2}=0,75$

$5 \% \mathrm{PA}=0,392+0,0081 \mathrm{C}, \mathrm{CV}=23,126, \mathrm{R}^{2}=0,76$

${ }^{6} \mathrm{~kg}=0,584+0,038 \mathrm{C}, \mathrm{CV}=27,326, \mathrm{R}^{2}=0,84$.

$7 \% \mathrm{PCVZ}=0,155+0,011 \mathrm{C}, \mathrm{CV}=22,968, \mathrm{R}^{2}=0,88$

$8 \% \mathrm{PA}=0,126+0,0099 \mathrm{C}, \mathrm{CV}=23,086, \mathrm{R}^{2}=0,89$

$9 \mathrm{~kg}=1,968-0,012 \mathrm{C}, \mathrm{CV}=26,495, \mathrm{R}^{2}=0,47$.

$10 \% \mathrm{PCVZ}=0,55-0,0033 \mathrm{C}, \mathrm{CV}=24,380, \mathrm{R}^{2}=0,62$.

$11 \% \mathrm{PA}=0,483-0,0028 \mathrm{C}, \mathrm{CV}=25,055, \mathrm{R}^{2}=0,62$

$\mathrm{C}=$ nível de concentrado na dieta 
Tabela 8 - Peso do conjunto dos componentes externos, órgãos vitais, trato gastrintestinal, gorduras interna e sangue de tourinhos superjovens terminados em confinamento com dietas com diferentes níveis de concentrado

\begin{tabular}{|c|c|c|c|c|c|c|c|}
\hline \multirow[t]{2}{*}{ Variável } & \multicolumn{4}{|c|}{ Nível de concentrado (\%) } & \multirow[t]{2}{*}{ Média } & \multirow[t]{2}{*}{ Erro-padrão } & \multirow[t]{2}{*}{ Probabilidad } \\
\hline & 22 & 40 & 59 & 79 & & & \\
\hline Componentes externos, $\mathrm{kg}$ & 65,27 & 65,19 & 61,20 & 63,25 & 63,73 & 3,81 & 0,855 \\
\hline Componentes externos, \% PCVZ & 18,58 & 17,92 & 17,33 & 17,78 & 17,9 & 0,70 & 0,611 \\
\hline Componentes externos, \% PA & 16,39 & 16,04 & 15,65 & 16,14 & 16,05 & 0,62 & 0,868 \\
\hline Órgãos vitais, $\mathrm{kg}$ & 10,59 & 11,56 & 11,30 & 11,45 & 11,23 & 0,08 & 0,810 \\
\hline Órgãos vitais, \% PCVZ & 3,01 & 3,20 & 3,20 & 3,20 & 3,15 & 0,08 & 0,266 \\
\hline Órgãos vitais, \% PA & 2,65 & 2,87 & 2,94 & 2,91 & 2,83 & 0,09 & 0,181 \\
\hline Trato gastrintestinal, $\mathrm{kg}$ & 15,36 & 16,93 & 19,06 & 18,63 & 17,49 & 1,39 & 0,272 \\
\hline Trato gastrintestinal, $\% \mathrm{PCVZ}^{1}$ & 4,38 & 4,67 & 5,38 & 5,20 & 4,91 & 0,16 & 0,003 \\
\hline Trato gastrintestinal, \% $\mathrm{PA}^{2}$ & 3,87 & 4,17 & 4,86 & 4,72 & 4,40 & 0,13 & 0,001 \\
\hline Gordura interna, $\mathrm{kg}$ & 18,26 & 22,63 & 21,10 & 22,90 & 21,22 & 1,67 & 0,240 \\
\hline Gordura interna, \% $\mathrm{PCVZ}^{3}$ & 5,16 & 6,25 & 5,95 & 6,40 & 5,94 & 0,32 & 0,041 \\
\hline Gordura interna, $\% \mathrm{PA}^{4}$ & 4,55 & 5,59 & 5,37 & 5,81 & 5,33 & 0,29 & 0,022 \\
\hline Sangue, $\mathrm{kg}$ & 9,72 & 9,65 & 10,52 & 10,72 & 10,16 & 0,15 & 0,876 \\
\hline Sangue, \% PCVZ & 2,76 & 2,70 & 2,97 & 2,96 & 2,84 & 0,18 & 0,581 \\
\hline Sangue, \% PA & 2,44 & 2,39 & 2,69 & 2,69 & 2,55 & 0,18 & 0,507 \\
\hline
\end{tabular}

${ }^{1} \mathrm{CTGI}, \% \mathrm{PCVZ}=4,080+0,017 \mathrm{C}, \mathrm{CV}=08,128, \mathrm{R}^{2}=0,64$.

2 CTGI, \% PA $=3,554+0,017 \mathrm{C}, \mathrm{CV}=07,893, \mathrm{R}^{2}=0,69$.

${ }^{3} \mathrm{CGI}, \% \mathrm{PCVZ}=5,05+0,078 \mathrm{C}, \mathrm{CV}=11,290, \mathrm{R}^{2}=0,62$

${ }^{4} \mathrm{CGI}, \% \mathrm{PA}=4,40+0,019 \mathrm{C}, \mathrm{CV}=11,471, \mathrm{R}^{2}=0,68$

$\mathrm{C}=$ nível de concentrado na dieta.

mobilização de nutrientes para deposição dessa gordura tem menor prioridade que o crescimento de tecidos do trato gastrintestinal.

O peso absoluto e os pesos relativos para o $\mathrm{CCE}$ e COV não foram alterados $(\mathrm{P}>0,05)$ pelo nível de concentrado na dieta, fato atribuído às variações individuais do peso de seus componentes. Neste estudo, não seria coerente inferir que as exigências de mantenças dos animais tenham sido influenciadas pelo conjunto de órgãos vitais, já que apresentaram pesos semelhantes.

O peso absoluto para CTGI não variou $(\mathrm{P}>0,05)$ com os níveis de concentrado na dieta e representou na média dos tratamentos 4,5\% do peso corporal. Quando o peso do CTGI foi expresso em porcentagem do PCVZ e PA, verificou-se aumento para ambas as variáveis de $0,017 \%$ a cada $1 \%$ a mais de concentrado na dieta, resultado relacionado principalmente ao aumento do peso de intestino. Ferreira et al. (2000) verificaram diminuição linear dos pesos absoluto e relativo do CTGI com a elevação do concentrado na dieta atribuíram esse resultado ao maior teor de FDN nas dietas com menores proporções de concentrado. Neste estudo, não foi verificada associação significativa entre o teor de FDN e os pesos relativos do CTGI. Segundo Koslozki (2001), os tecidos viscerais representam aproximadamente $6 \%$ do corpo vazio, mas são responsáveis pelo consumo de $41 \%$ do total de energia gasta, em razão da maior atividade metabólica destes tecidos. Neste estudo, da mesma forma que o peso relativo do CTGI, o ganho de peso médio diário (GMD) e o consumo de energia digestível (Missio et al., 2009) aumentaram linearmente com a quantidade de concentrado na dieta. Embora numericamente o GMD entre os dois maiores níveis de concentrado tenha sido próximo, não seria prudente inferir que houve aumento significativo na exigência de energia de mantença, visto que os dados de consumo de energia e desempenho animal (Missio et al., 2009) não suportam essa afirmação.

O peso do conteúdo de gordura interna expresso em quilogramas não foi influenciado significativamente pelo nível de concentrado na dieta. Entretanto, quando os valores foram expressos em porcentagem do PCVZ e peso de abate, verificou-se maior quantidade de gordura interna para níveis superiores de concentrado na dieta, confirmando os resultados obtidos por Ferreira et al. (2000) e Véras et al. (2001). Houve associação positiva dos pesos relativos do conteúdo de gordura interna com o GMD $(\mathrm{r}=0,76 ; \mathrm{P}=0,0006)$ e o consumo de energia $(\mathrm{r}=0,78$; $\mathrm{P}=0,0003)$. Esses resultados são coerentes também com o relato de Robelin \& Geay (1984) de que o aumento no consumo de energia geralmente eleva a deposição de gordura no corpo do animal. Segundo Owens et al. (1995), maiores depósitos de gordura cavitária ocasionam maiores exigências para mantença, em razão da maior atividade metabólica do tecido adiposo, fato que não pode ser diagnosticado neste trabalho. Outro ponto importante relacionado ao aumento da quantidade de gordura interna é o efeito sobre o rendimento de carcaça, que pode determinar menores rendimentos de carcaça, uma vez que a gordura interna é contabilizada no PCVZ e não agrega 
peso à carcaça, diminuindo a porcentagem de participação da carcaça no PCVZ.

A dificuldade de visualização de forma indireta em termos de diferenças para as exigências de mantença pode estar relacionada ao fato de que os animais foram abatidos com peso vivo semelhante. Segundo McDonald et al. (1995), o peso vivo é o principal determinante da composição corporal e das exigências nutricionais para crescimento. Corroborando, Veloso et al. (2002) afirmaram que em bovinos com tamanho semelhante à maturidade, 95,6 a $98,9 \%$ da variação nos componentes químicos e na energia retida no corpo vazio estão associados à variação do peso vivo.

O conteúdo sangüíneo dos animais em geral tem como função principal oxigenar os tecidos e carrear os nutrientes absorvidos ou mobilizados para as diversas partes do corpo para que sejam depositados ou utilizados para manter as funções vitais do organismo. Neste estudo, o aumento do concentrado na dieta não influenciou $(\mathrm{P}>0,05)$ o peso de sangue nas três formas na qual foi expresso, o que pode estar relacionado à semelhança no peso de abate e conjunto de órgãos vitais, visto que estas variáveis se correlacionaram significativamente com o peso de sangue (0,64 e 0,84 , respectivamente). Ribeiro et al. (2001) verificaram aumento no peso de sangue em animais alimentados com maiores níveis de concentrado na dieta e atribuíram esse aumento ao maior peso dos órgãos internos e componentes do trato gastrintestinal dos animais. Clementino et al. (2007), no entanto, avaliando a influência de níveis crescentes de concentrado na dieta de ovinos confinados, atribuíram o aumento do peso de sangue ao maior peso de abate dos animais.

Existem poucos trabalhos na literatura sobre o efeito do nível de concentrado ou de energia sobre a quantidade de sangue corporal, o que dificulta a comparação de resultados. Todavia, a partir dos dados deste estudo e dos autores supracitados, parece que o conteúdo desse componente só é alterado pelo aumento da proporção de concentrado na dieta quando o tamanho do corpo, órgãos internos e trato gastrintestinal são substancialmente alterados. Além disso, em geral, independentemente do componente, o peso absoluto dos não-componentes da carcaça pode não indicar se haverá influência ou não quando quantidades diferentes de concentrado forem fornecidas.

\section{Conclusões}

O aumento do nível de concentrado na dieta de 22 para $79 \%$ promoveu aumento nos pesos relativos do conteúdo do trato gastrintestinal e da gordura interna, mas não influenciou o conjunto dos órgãos internos, o peso de corpo vazio e o rendimento de carcaça ajustado para o peso de corpo vazio de tourinhos abatidos aos 14-16 meses de idade e $400 \mathrm{~kg}$.

\section{Agradecimentos}

Ao Departamento de Zootecnia/UFSM, à Capes e ao CNPq.

\section{Literatura Citada}

ALMEIDA, M.I.V.; FONTES, C.A.A.; ALMEIDA, F.Q. et al Avaliação do crescimento de tecidos e órgãos de novilhos mestiços holandês-Gir durante o ganho compensatório. 2. Tecidos e órgãos. Revista Brasileira de Zootecnia, v.30, n.2, p.535-545, 2001.

ANUALPEC - Anuário da Pecuária Brasileira. 13.ed. São Paulo: Instituto FNP, 2006. 369p.

BLACK, L.L. Crecimiento y desarrollo de corderos. In: HARESIGN, W. (Ed.) Producción ovina. México: AGT Editor, 1989. p. $23-62$.

CARVAlHO, P.A.; SANCHES, L.M.B.; VIÉGAS, J. et al. Componentes do peso vivo e órgãos viscerais de bezerros machos de origem leiteira ao nascimento, 50 e 110 dias de vida. Revista Brasileira de Zootecnia, v.32, n.6, p.1469$1475,2003$.

COLEMAN, S.W.; EVANS, B.C.; GUENTHER, J.J. Body and carcass composition of Angus and Charolais steers as affected by age and nutrition. Journal of Animal Science, v.71, n.1, p.8695, 1993.

CLEMENTINO, R.H.; SOUSA, W.H.; MEDEIROS, A.N. et al. Influência dos níveis de concentrado sobre os cortes comerciais, os constituintes não-carcaça e os componentes da perna de cordeiros confinados. Revista Brasileira de Zootecnia, v.36, n.3, p.681-688, 2007.

FERREIRA, M.A.; VALADARES FILHO, S.C.; MUNIZ, E.B. et al Características das carcaças, biometria do trato gastrintestinal, tamanho dos órgãos internos e conteúdo gastrintestinal de bovinos F1 Simental x Nelore alimentados com dietas contendo vários níveis de concentrado. Revista Brasileira de Zootecnia, v.29, n.4, p.1174-1182, 2000.

FERREL, C.L.; GARRET, W.N.; HINMAN, N. Estimation of body composition in pregnant and non pregnant heifers. Journal of Animal Science, v.42, n.5, p.1158-1166, 1976.

FERREL, C.L.; JENKINS, T.G. Body composition and energy utilization by steers of diverse genotypes fed a high concentrate diet during the finishing period: I: Angus, Belgian Blue, Hereford, and Piedmontese. Journal of Animal Science, v.76, n.2, p.637-646, 1998.

JORGE, A.M.; FONTES, C.A.A. Desenvolvimento relativo das partes do corpo de zebuínos de quatro raças. Ciência Rural, v. 31, n.5, p.857-81, 2001 .

KOSLOSKI, G.V. Bioquímica dos ruminantes. Santa Maria Universidade Federal de Santa Maria, 2001. 140p.

LUCCI, C.S. Bovinos leiteiros jovens. São Paulo: Nobel/EDUSP, 1989. $371 \mathrm{p}$.

McDONALD, P.; EDWARDS, R.A.; GREENHALGH, J.F.D. et al Animal nutrition. 5.ed. Singapore: Longman, 1995. 607p.

MACITELLI, F.; BERCHIELLI, T.T.; SILVEIRA, R.N. et al. Biometria da carcaça e peso de vísceras e de órgãos internos de bovinos mestiços alimentados com diferentes volumosos e fontes protéicas. Revista Brasileira de Zootecnia, v.34, n.5, p.1751-1762, 2005 . 
MISSIO, R.L. Níveis de concentrado na dieta de bovinos. 2007. 108f. Dissertação (Mestrado em Zootecnia) - Universidade Federal de Santa Maria, Santa Maria, 2007.

MISSIO, R.L.; BRONDANI, I.L.; FREITAS, L.S. et al. Desempenho e avaliação econômica da terminação de tourinhos em confinamento alimentados com diferentes níveis de concentrado na dieta. Revista Brasileira de Zootecnia, 2009 (no prelo).

OWENS, F.N.; DUBESKI, P.; HANSON, C.F. Factors that alter the growth and development of ruminants. Journal of Animal Science, v.71, n.11, p.3138-3150, 1993.

OWENS, F.N.; GILL, D.R.; SECRIST, D.S. et al. Review of some aspects of growth and development of feedlot cattle. Journal of Animal Science, v.73, n.10, p.3152-3172, 1995.

PACHECO, P.S.; RESTLE, J.; SILVA, J.H.S. et al. Características das partes do corpo não-integrantes da carcaça de novilhos jovens e superjovens de diferentes grupos genéticos. Revista Brasileira de Zootecnia, v.34, n.5, p.1678-1690, 2005.

PERÓN, A.J.; FONTES, C.A.A.; LANA, R.P. et al. Tamanho de órgãos internos e distribuição da gordura corporal, em novilhos de cinco grupos genéticos, submetidos à alimentação restrita e ad libitum. Revista da Sociedade Brasileira de Zootecnia, v.22, n.5, p.813-819, 1993.

PETIT, H.V.; VEIRA, D.M.; YU, Y. Growth and carcass characteristics of beef steers fed silage and different levels of energy with or without protein supplementation. Journal of Animal Science, v.72, n.12, p.3221-3229, 1994.

RIBEIRO, T.R.; PEREIRA, J.C.; LEÃO, M.I. et al. Tamanho de órgãos e vísceras de bezerros holandeses, para produção de vitelos, recebendo dietas com diferentes níveis de concentrado. Revista Brasileira de Zootecnia, v.30, n.6, p.2163- 2168, 2001 (supl.).
ROBELIN, J.; GEAY, Y. Body composition of cattle as affected by physiological status, breed, sex and diet. In: GILCHRIST, F.M.C.; MACKIE, R.I. (Eds.) herbage nutrition in the subtropics and tropics. Johannesburg: Science Press, 1984. p.525-547.

ROHR, K.; DAENICKE, R. Nutritional effects on the distribution of live weight as gastrointestinal tract fill and tissue components in growing cattle. Journal of Animal Science, v. 58, n. 3 , p.753-765, 1984

STATISTICAL ANALYSIS SYSTEM - SAS. SAS'S user's guide. SAS for Windows. Cary: SAS Institute, 1997. 46p.

SIGNORETTI, R.D.; COELHO DA SILVA, J.F.; VALADARES FILHO, S.C. et al. Crescimento, conversão alimentar e rendimento de carcaça de bezerros da raça holandesa alimentados com dietas contendo diferentes níveis de volumoso. Revista Brasileira de Zootecnia, v.28, n.1, p.185-194, 1999.

SILVA, F.F.; VALADARES FILHO, S.C.; ÍTAVO, L.C.V. et al. Consumo, desempenho, características de carcaça e biometria do trato gastrintestinal e dos órgãos internos de novilhos Nelore recebendo dietas com diferentes níveis de concentrado e proteína. Revista Brasileira de Zootecnia, v.31, n.4, p.1849-1864, 2002.

Van SOEST, P.J. Nutritional ecology of the ruminant. 2.ed. Ithaca: Cornell University Press, 1994. 476p.

VELOSO, C.M.; VALADARES FILHO, S.C.; GESUALDI JR., A. et al. Composição corporal e exigências energéticas e protéicas de bovinos F1 Limousin x Nelore, não-castrados, alimentados com rações contendo diferentes níveis de concentrado. Revista Brasileira de Zootecnia, v.31, n.3, p.1273-1285, 2002.

VÉRAS, A.S.C.; VALADARES FILHO, S.C.; SILVA, J.F.C. et al. Efeito do nível de concentrado sobre o peso dos órgãos internos e do conteúdo gastrintestinal de bovinos nelore não-castrados. Revista Brasileira de Zootecnia, v.30, n.3, p.1120-1126, 2001 (supl. 1). 